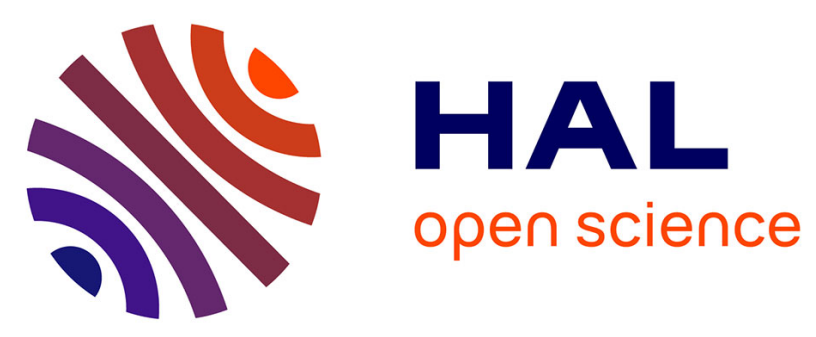

\title{
Hydroxyapatites: Key Structural Questions and Answers from Dynamic Nuclear Polarization
}

César Leroy, Fabien Aussenac, Laure Bonhomme-Coury, Akiyoshi Osaka, Satoshi Hayakawa, Florence Babonneau, Cristina Coelho-Diogo, Christian Bonhomme

\section{To cite this version:}

César Leroy, Fabien Aussenac, Laure Bonhomme-Coury, Akiyoshi Osaka, Satoshi Hayakawa, et al.. Hydroxyapatites: Key Structural Questions and Answers from Dynamic Nuclear Polarization. Analytical Chemistry, 2017, 89 (19), pp.10201 - 10207. 10.1021/acs.analchem.7b01332 . hal-01611666

\section{HAL Id: hal-01611666 https://hal.sorbonne-universite.fr/hal-01611666}

Submitted on 6 Oct 2017

HAL is a multi-disciplinary open access archive for the deposit and dissemination of scientific research documents, whether they are published or not. The documents may come from teaching and research institutions in France or abroad, or from public or private research centers.
L'archive ouverte pluridisciplinaire HAL, est destinée au dépôt et à la diffusion de documents scientifiques de niveau recherche, publiés ou non, émanant des établissements d'enseignement et de recherche français ou étrangers, des laboratoires publics ou privés. 


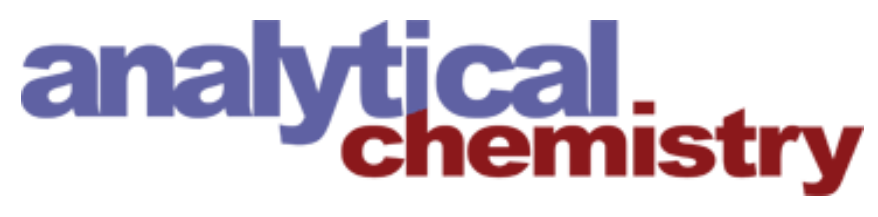

Subscriber access provided by BUPMC - Bibliothèque Universitaire Pierre et Marie Curie

Article

Hydroxyapatites: Key Structural Questions and
Answers from DNP (Dynamic Nuclear Polarization)

Cesar Leroy, Fabien Aussenac, Laure Bonhomme-Coury, Akiyoshi OSAKA, Satoshi

Hayakawa, Florence Babonneau, Cristina Coelho Diogo, and Christian Bonhomme

Anal. Chem., Just Accepted Manuscript • DOI: 10.1021/acs.analchem.7b01332 • Publication Date (Web): 05 Sep 2017

Downloaded from http://pubs.acs.org on September 7, 2017

\section{Just Accepted}

"Just Accepted" manuscripts have been peer-reviewed and accepted for publication. They are posted online prior to technical editing, formatting for publication and author proofing. The American Chemical Society provides "Just Accepted" as a free service to the research community to expedite the dissemination of scientific material as soon as possible after acceptance. "Just Accepted" manuscripts appear in full in PDF format accompanied by an HTML abstract. "Just Accepted" manuscripts have been fully peer reviewed, but should not be considered the official version of record. They are accessible to all readers and citable by the Digital Object Identifier (DOI®). "Just Accepted" is an optional service offered to authors. Therefore, the "Just Accepted" Web site may not include all articles that will be published in the journal. After a manuscript is technically edited and formatted, it will be removed from the "Just Accepted" Web site and published as an ASAP article. Note that technical editing may introduce minor changes to the manuscript text and/or graphics which could affect content, and all legal disclaimers and ethical guidelines that apply to the journal pertain. ACS cannot be held responsible for errors or consequences arising from the use of information contained in these "Just Accepted" manuscripts. 


\begin{abstract}
We demonstrate that NMR/DNP (Dynamic Nuclear Polarization) allows an unprecedented description of carbonate substituted hydroxyapatite (CHAp). Key structural questions related to order/disorder and clustering of carbonates are tackled by using distance sensitive DNP experiments using ${ }^{13} \mathrm{C}^{13} \mathrm{C}$ recoupling. Such experiments are easily implemented due to unprecedented DNP gain (orders of magnitude). DNP is efficiently mediated by quasi one-dimensional spin diffusion through the hydroxyl columns present in the CHAp structure (thought as "highways" for spin diffusion). For spherical nanoparticles and $\varnothing<100 \mathrm{~nm}$, it is numerically shown that spin diffusion allows their study as a whole. Most importantly, we demonstrate also that the DNP study at $100 \mathrm{~K}$ leads to data which are comparable to data obtained at room temperature (in terms of spin dynamics and lineshape resolution). Finally, all 2D DNP experiments can be interpreted in terms of domains exhibiting well identified types of substitution: local order and carbonate clustering are clearly favored.
\end{abstract}

\section{INTRODUCTION}

Nanosized substituted hydroxyapatite (HAp) is a fundamental mineral in nature, as it represents the key mineral architecture in bone, dentin and enamel (biological apatites) $^{1,2}$. Moreover, synthetic substituted HAp (including carbonated HAp, CHAp) is extensively used in medicine and dentistry due to its exceptional bioactivity and biocompatibility properties ${ }^{3}$. Despite numerous physicochemical analyses (X-ray and neutron diffraction, vibrational spectroscopies, thermal analyses...), the structural description of substituted apatites remains largely hypothetical and particularly challenging. Focusing on the particular case of carbonate substitution, Leventouri ${ }^{4}$ stressed a fundamental crystal structure problem related to the precise location of carbonates in CHAp known as the "carbonate substitution problem" ${ }^{5,6}$ in A $\left(\mathrm{OH}^{-}\right)$ and/or B $\left(\mathrm{PO}_{4}{ }^{3-}\right)$ sites. Quoting Ren et al. in $2014^{7}$ :

"Due to very limited information on direct structural analysis of carbonated HAp quality single crystals, the exact location of $\mathrm{CO}_{3}{ }^{2-}$ in apatite is still a mystery".

Two fundamental questions can be raised, namely (i) the notion of order/disorder in CHAp, (ii) the potential clustering of the substituted anions/cations in HAp. To tackle such questions, XRD and FTIR suffer from major drawbacks, i.e. the long range order averaged description of the atomic positions, and the very local description of chemical groups, respectively. Theoretically, the ability of solid state NMR to establish through space connectivities should fill the gap between very local properties and long-range order features. Apart from sensitive nuclei $\left({ }^{1} \mathrm{H}\right.$, $\left.{ }^{31} \mathrm{P}\right)^{8,9,10,11,12,13,14,15}$, all other nuclei present as substitutions suffer from severe sensitivity limitations due to low natural abundance $\left({ }^{13} \mathrm{C}, 1.1 \%\right)$ and/or intrinsic low $\mathrm{wt} \%{ }^{16,17}$. It precluded so far the routine use of dipolar based triple resonance experiments $\left({ }^{1} \mathrm{H}-\mathrm{X}-\mathrm{Y} ; \mathrm{X}, \mathrm{Y}={ }^{13} \mathrm{C}\right.$, $\left.{ }^{31} \mathrm{P} . ..\right)$ which should probe the spatial distribution even in the case of partially disordered materials.

To circumvent this limitation, Dynamic Nuclear Polarization (DNP) was implemented here for the first time, following the work of Griffin et al. ${ }^{18}$. DNP corresponds to the efficient transfer of polarization at low temperature $(\sim 100 \mathrm{~K})$ from unpaired electrons (present in radicals or biradicals such as TOTAPOL ${ }^{19}$ or AMUPol $^{20}$ ) to NMR active nuclei. The gain in notoriety of DNP is associated to very large gain in sensitivity (several orders in magnitude) and impressive applications for low abundant nuclei $^{21,22,23,24,25,26,27,28,29,30,31,32,33,34,35}$.

In this contribution, we claim that DNP opens new avenues for unprecedented characterization of CHAp and 
allows answering the key questions raised above (points (i) and (ii)). The proposed methodology can be extended to all types of substitutions, as soon as one NMR active nucleus is present. In the case of CHAp nanoparticles, DNP and proton spin diffusion (SD) allow the global characterization of a given nanoparticle, including its surface and core. We estimate the limit diameter for which the core contribution will be underestimated during the DNP/SD process to $\sim 500 \mathrm{~nm}$. The DNP efficiency allows recording $2 \mathrm{D}$ triple resonance experiments within an hour (instead of days or even months). Full assignments of the NMR lines are proposed, as well as very first realistic schemes for the substitutions. We mention here that CHAp nanoparticles have been studied recently in the frame of ${ }^{1} \mathrm{H}-{ }^{43} \mathrm{Ca}$ DNP CP MAS experiments ${ }^{36}$. It has been claimed that such technique was suitable for site selection (CHAp nanoparticle surface $v$ s core species). We stress here that such selection is by no means related to the SENS acceptance ${ }^{21}$ of DNP, namely Surface Enhanced NMR Spectroscopy. Due to the very large DNP enhancements (using glycerol in ${ }^{36}$ ), $2 \mathrm{D}{ }^{1} \mathrm{H}-{ }^{43} \mathrm{Ca}$ DNP HETCOR experiments were implemented leading to the observation of clear correlations between ${ }^{43} \mathrm{Ca}$ nuclei and $\mathrm{OH}^{-}$ species (located in the columns) and protons belonging to the solvent. Such correlations were attributed to distinct species without particular selectivity. It has to be mentioned that the use of glycerol adds complexity in terms of chemistry (chemical bonding, potential partial dissolution) and spin dynamics. The study presented below is by far more simple as $\mathrm{D}_{2} \mathrm{O} / \mathrm{H}_{2} \mathrm{O}$ is used as DNP solvent.

All in all, the DNP approach unifies standard characterizations (including diffraction and vibrational methods $)^{2,4,5,37}$, theoretical modeling of CHAp structures ${ }^{38,39,40}$ and breaks the barriers in understanding the CHAp structure.

\section{RESULTS AND DISCUSSION}

CHAp: a prototype for DNP and one-dimensional ${ }^{1} \mathbf{H}-{ }^{1} \mathbf{H}$ spin diffusion (SD). The fundamental feature of CHAp is the presence of $\mathrm{OH}^{-}$columns parallel to the $c$-axis (Figure 1a). It follows that one-dimensional ${ }^{1} \mathrm{H}$ SD can be considered as a reasonable approximation. Taking into account the structural characteristics of HAp, the diffusivity, $\mathrm{D}$, along the channels is estimated to $\mathrm{D}$ $\sim 0.5 \mathrm{~nm}^{2} . \mathrm{ms}^{-1}$ (see Supporting information). The protons in close contact with the surface of the nanoparticles are first DNP polarized (Figure $1 \mathrm{~b}$ ). Protons located in the core of the nanoparticles are subsequently polarized by SD. ${ }^{41,42,43,44,45}$ We demonstrate unambiguously that in the case of nanoparticles of $\varnothing \sim 30 \mathrm{~nm}$ (Figure $\mathrm{S} 1$ ), all protons are indeed polarized. This assumption still holds under moderated MAS conditions $\left(v_{\text {rot }}=8 \mathrm{kHz}\right.$ ) (see Supporting information).

DNP enhancement for synthetic CHAp nanoparticles: ${ }_{1 D}$ and ${ }_{2} D{ }^{31} \mathrm{P}-{ }^{13} \mathrm{C}$ and ${ }^{13} \mathrm{C}-{ }^{13} \mathrm{C}$ distance sensitive experiments. The syntheses of ${ }^{13} \mathrm{C}$ labeled (CHAp) and natural abundance (n.a.CHAp) samples are presented in the Experimental section, as well as the sample preparation for DNP experiments. Figure 2 shows the DNP efficiency for ${ }^{1} \mathrm{H},{ }^{31} \mathrm{P}$ and ${ }^{13} \mathrm{C}$ (CHAp). The DNP enhancement is further increased by using AMUPol instead of TOTAPOL and reached $\varepsilon \sim 23$ for all observed nuclei. The reduction in experimental time can be roughly estimated by $\varepsilon^{2} \sim 550$. The ${ }^{1} \mathrm{H} \rightarrow{ }^{31} \mathrm{P}$ DNP spectrum is characteristic for a substituted HAp $\left(\delta_{\text {iso }}\left({ }^{31} \mathrm{P}\right) \sim 3.0 \mathrm{ppm}\right)$ and exhibits a broadening of the line when compared to pure $\mathrm{HAp}^{12}$. The content in $\mathrm{HPO}_{4}{ }^{2-}$ is negligible ${ }^{10,13}$ as demonstrated by $2 \mathrm{D}{ }^{1} \mathrm{H} \rightarrow{ }^{31} \mathrm{P}$ HETCOR CP MAS experiments implemented at room temperature (RT) (Figure S2). Remarkably, the ${ }^{13} \mathrm{C}$ resolution is clearly sufficient to distinguish both $\mathrm{A}$ and $\mathrm{B}$ sites contributions (four main isotropic ${ }^{13} \mathrm{C}$ resonances) and comparable to the one observed using standard NMR at RT (Figure $\mathrm{S}_{3}$ ). Moreover, the $\mathrm{CP}$ dynamics is comparable, both at $100 \mathrm{~K}$ and RT (Figure $\mathrm{S}_{4}$ ). The detailed analyses of the variable contact time curves showed also that no $\mathrm{HCO}_{3}{ }^{-}$species were involved (Figure $\left.\mathrm{S}_{5}\right)^{17}$. It follows that the DNP data obtained at $\sim 100 \mathrm{~K}$ can be safely compared to those obtained at RT and that the conclusions derived from the DNP methodology are indeed representative of CHAp.

${ }^{1} \mathrm{H} \rightarrow{ }^{31} \mathrm{P} \rightarrow{ }^{13} \mathrm{C}$ DNP double CP MAS experiments were successfully implemented (Figure $3 a$, black line) in a very short experimental time $(\sim 3 \mathrm{~min}$.). In the particular case of CHAp, only double resonance experiments $\left({ }^{1} \mathrm{H} \rightarrow{ }^{13} \mathrm{C}\right)$ were proposed so far in the literature for ${ }^{13} \mathrm{C}$ labeled samples $^{17}$. In Figure $3 \mathrm{~b}$, the corresponding $2 \mathrm{D}$ HETCOR experiment (obtained in less than 4 hours) is presented. Each ${ }^{13} \mathrm{C}$ resonance is individually connected to ${ }^{31} \mathrm{P}$ components which are slightly different in terms of $\delta_{\text {iso }}\left({ }^{31} \mathrm{P}\right)$. Moreover, a fraction of $\mathrm{B}$ sites is slightly correlated to a deshielded component of the ${ }^{31} \mathrm{P}$ spectrum $\left(\delta_{\text {iso }}{ }^{31} \mathrm{P} \sim 5.6 \mathrm{ppm}\right)$. The DNP efficiency was sufficient to implement the same experiment for n.a.CHAp (Figure S6, 10 hours) leading to very comparable information. Such experiment would have been impossible to implement using standard NMR at room temperature!

Finally, ${ }^{1} \mathrm{H} \rightarrow{ }^{13} \mathrm{C} \rightarrow{ }^{13} \mathrm{C}$ DNP MAS experiments based on double quantum (DQ) dipolar recoupling ${ }^{46}$ were successfully implemented (Figure $3 c, \sim 7$ hours). In principle, such a sequence should highlight spatial connectivities between the carbonate groups. Despite the very small $\delta_{\text {iso }}\left({ }^{13} \mathrm{C}\right)$ chemical shift range $(\sim 5 \mathrm{ppm})$, a remarkable resolution is obtained in both dimensions. Several offdiagonal correlations are observed (for instance at $\delta_{\text {iso }}\left({ }^{13} \mathrm{C}\right)_{B / B}=170.1$ and $\left.171.0 \mathrm{ppm}\right)\left({ }^{13} \mathrm{C}\right.$ sites exhibiting different chemical environments) as well as on-diagonal correlation $\left(\delta_{\text {iso }}\left({ }^{13} \mathrm{C}\right)_{B / \boldsymbol{B}}=168.3 \mathrm{ppm}\right)$ (same chemical environment). We recall here that the amount of carbonates is very small (roughly $5 \mathrm{wt} \%$ ) and that ${ }^{13} \mathrm{C}$ labeling is therefore mandatory for the implementation of the ${ }^{13} \mathrm{C} D Q$ experiments.

Towards a definitive picture of carbonates in CHAp. The goal of this last section is to derive realistic CHAp 
models from the set of DNP data described above. Considering the connectivities between carbonates, Figure $3 \mathrm{C}$ is the most informative. The clear observation of at least nine individual ${ }^{13} \mathrm{C}$ correlations (shown by arrows) in a $\sim 5 \mathrm{ppm}$ shift range proves that local order is definitely present (leading to well defined chemical environment for each ${ }^{13} \mathrm{C}$ nucleus) (see also Figure $\mathrm{S}_{7}$ and the Experimental section). The slices in Figure $3 c$ are presented without any GB treatment in order to avoid the presence of artefacts. We have checked that the indirect chemical shifts for i), ii), iii) and iv) correspond to the sums of the involved (direct) chemical shifts (Figure $\mathrm{S}_{7}$ ). Charge compensation is the key concept and several authors have proposed the following favorable replacement schemes (based on experimental observations ${ }^{2,4,5,7,37}$ and energy minimiza$\left.\operatorname{tion}^{38,39,4^{\circ}}\right)$ :

(1) A substitution: $\mathrm{CO}_{3}{ }^{2-}=2 \mathrm{OH}^{-}$

(2) A/B substitution: $2 \mathrm{CO}_{3}^{2-}=\mathrm{OH}^{-}+\mathrm{PO}_{4}^{3-}$

(3) B/B substitution: $\square_{\mathrm{Ca} 2+}+2 \mathrm{CO}_{3}{ }^{2-}=\mathrm{Ca}^{2+}+2 \mathrm{PO}_{4}^{3-}$

We use here Fleet's notations showing the substituting constituents on the left hand side of the equation. We neglect a forth possible scheme (B substitution), $\mathrm{Na}^{+}+\mathrm{CO}_{3}{ }^{2-}=\mathrm{Ca}^{2+}+\mathrm{PO}_{4}{ }^{3-}$, as the $\mathrm{Na}$ wt $\%$ is small (see the Experimental section).

At first sight, the multiplicity of B/B contributions (eq. (3)) in Figure $3 \mathrm{c}$ is complex to analyze and needs some invention at this point. Indeed, strong (off-diagonal) and much less intense (off- and on-diagonal) correlations are observed (vide supra). We assume first that correlations correspond to the shortest distances between ${ }^{13} \mathrm{C}$ sites. In pure HAp (Figure $4 \mathrm{a})$, the shortest $\mathrm{d}_{(\mathrm{P}-\mathrm{P})}$ distances $(\sim 4.0$ $\AA$ ) are found in zig-zag chains with overall $c$-axis direction: $\mathrm{B} / \mathrm{B}$ association corresponds to consecutive positions in a given chain. Considering a single $\mathrm{B} / \mathrm{B}$ group $\left(\mathrm{C}_{1} / \mathrm{C}_{2}\right.$, Figure $4 \mathrm{~b}$, left $)$ in $\mathrm{Ca}_{19}\left(\mathrm{PO}_{4}\right)_{10}\left(\mathrm{CO}_{3}\right)_{2(\boldsymbol{B} / \boldsymbol{B})}(\mathrm{OH})_{4}\left(\mathrm{wt} \%\left(\mathrm{CO}_{3}{ }^{2-}\right)\right.$ $=6.3 \%)$, a vacancy $\left(\square_{\mathrm{Ca} 2+}\right)$ is present near one of the carbonate, leading consequently to $\delta_{\text {iso }}\left({ }^{13} \mathrm{C}_{1}\right) \neq \delta_{\text {iso }}\left({ }^{13} \mathrm{C}_{2}\right)$ and off-diagonal correlations in the ${ }^{13} \mathrm{CDQ}$ spectrum. We assign the intense correlations at $\delta_{\text {iso }}\left({ }^{13} \mathrm{C}\right)_{B / \boldsymbol{B}}=170.1$ and 171.0 ppm to such $\mathrm{B} / \mathrm{B}$ groups. At this stage, the main challenge is to safely assign the less intense correlations. The on-diagonal correlation located at $\delta_{\text {iso }}\left({ }^{13} \mathrm{C}\right)_{B / \boldsymbol{B}}=$ $168.3 \mathrm{ppm}$ indicates that some carbonates must have somehow equivalent chemical environments (and the same chemical shifts), in clear contradiction with $\mathrm{B} / \mathrm{B}$ association described just above (as $\delta_{\text {iso }}\left({ }^{13} C_{1}\right) \neq \delta_{\text {iso }}\left({ }^{13} C_{2}\right)$, necessarily!). This intriguing fact can be explained as follows.

Consider now four carbonates $\left(C_{i}, \mathrm{i}: 1 \rightarrow 4\right)$ and two associated $\square_{\mathrm{Ca} 2+}$ along a given zig-zag chain, as shown in Figure $4 \mathrm{~b}$, right (HAp supercell, $\mathrm{Ca}_{38}\left(\mathrm{PO}_{4}\right)_{20}\left(\mathrm{CO}_{3}\right)_{4(\boldsymbol{B} / \boldsymbol{B})}(\mathrm{OH})_{8}$, with wt $\left.\%\left(\mathrm{CO}_{3}{ }^{2-}\right)=6.3 \%\right)$.
The relative location of $\square_{\mathrm{Ca} 2+}$ implies $C_{4}^{2}=6$ distinct configurations. We suppose that $\delta_{\text {iso }}\left({ }^{13} \mathrm{C}_{\mathrm{i}}\right)$ is mainly dominated by the effect of the first neighbors along the zig-zag chain. It follows that 8 distinct $\delta_{\text {iso }}\left({ }^{13} \mathrm{C}_{\mathrm{i}}\right) \equiv \delta_{\mathrm{m}}(\mathrm{m}: 1 \rightarrow 8)$ can be expected. In other words, a given ${ }^{13} \mathrm{C}_{\mathrm{i}}$ (Figure $4 \mathrm{~b}$, right) can be characterized by several $\delta_{\mathrm{m}}$. Taking into account all connectivities between consecutive ${ }^{13} \mathrm{C}_{\mathrm{i}}\left(\delta_{\mathrm{m}}\right)$ and ${ }^{13} \mathrm{C}_{\mathrm{j} \neq \mathrm{i}}$ $\left(\delta_{\mathrm{m}}\right)$ lead to a correlation map (Figure 4c) exhibiting both on- and off-diagonal correlations, in agreement with DQ data (at least qualitatively). This simple approach is further discussed in Figure S8 for potential correlations corresponding to longer ${ }^{13} \mathrm{C}-{ }^{13} \mathrm{C}$ distances.

Finally, one notes the absence of on-diagonal A/A correlations whereas off-diagonal $\mathrm{A} / \mathrm{B}$ correlations $\left(\delta_{\text {iso }}\left({ }^{13} \mathrm{C}\right)_{\boldsymbol{A} / \boldsymbol{B}}\right.$ $\left.=166.5 \mathrm{ppm}, \quad \delta_{\text {iso }}\left({ }^{13} \mathrm{C}\right)_{A / B}=168.0 \mathrm{ppm}\right)$ are clearly evidenced. This result unambiguously reveals A/B substitutions (eq. (2)) in absence of $\mathrm{A} / \mathrm{A}$ associations (eq. (1)). Moreover, as $\mathrm{d}_{\left({ }_{13} \mathrm{C}-13 \mathrm{C}\right)} \sim 3.90-4.02 \AA$ in $\mathrm{A} / \mathrm{B}$ associations ${ }^{38}$, it is concluded that the DQ experiment is effectively sensitive to $\mathrm{d}_{\left({ }_{13} \mathrm{C}-13 \mathrm{C}\right)}$ distances up to $\sim 4.0 \AA$ (at least) as presupposed in the analysis of $\mathrm{B} / \mathrm{B}$ correlations (vide supra). The A/B association can be represented by a supercell of formula $\mathrm{Ca}_{20}\left(\mathrm{PO}_{4}\right)_{11}\left(\mathrm{CO}_{3}\right)_{2(\boldsymbol{A} / \boldsymbol{B})}(\mathrm{OH})_{3}{ }^{38}\left(\mathrm{wt} \%\left(\mathrm{CO}_{3}{ }^{2-}\right)=5.9 \%\right.$, a value comparable to the experimental one).

However, DQ experiments are not sensitive to potential isolated $\mathrm{A}$ and/or $\mathrm{B}$ sites and therefore are not relevant to evidence their presence/absence. In the structure of $\mathrm{A}$ type $\mathrm{CHAp}^{38}$, each isolated A site is surrounded by six $\mathrm{PO}_{4}{ }^{3-}$ groups involving $\mathrm{d}_{\left({ }_{13} \mathrm{C}-31 \mathrm{P}\right)} \sim 3.89-4.09 \AA$ (instead of two or three $\mathrm{PO}_{4}{ }^{3-}$ for $\mathrm{B}$ and $\mathrm{A} / \mathrm{B}$ sites). It follows that isolated $\mathrm{A}$ sites should be specifically overestimated by ${ }^{31} \mathrm{P} \rightarrow{ }^{13} \mathrm{C} \mathrm{CP}$ transfer. Obviously, this is not the case experimentally (Figure $3 \mathrm{a}$ ), suggesting that A sites are mostly present in A/B combination. On the other hand, ${ }^{31} \mathrm{P}$ filtering leads to a slight overestimation of the resonance at $\delta_{\text {iso }}\left({ }^{13} \mathrm{C}\right) \sim 170.2 \mathrm{ppm}$. This can be assigned to isolated $\mathrm{B}$ sites having more $\mathrm{PO}_{4}{ }^{3-}$ neighbors than clustered B sites (vide supra and Figure $4 \mathrm{~b}$ ). These particular $\mathrm{B}$ sites are slightly correlated to a characteristic deshielded component of the ${ }^{31} \mathrm{P}$ spectrum $\left(\delta_{\text {iso }}\left({ }^{31} \mathrm{P}\right) \sim 5.6 \mathrm{ppm}\right)$ (Figure $3 \mathrm{~b})^{47}$.

All in all, CHAp nanoparticles can be safely understood as domains corresponding to clustered $\mathrm{B} / \mathrm{B}$ $\left(\mathrm{Ca}_{19}\left(\mathrm{PO}_{4}\right)_{10}\left(\mathrm{CO}_{3}\right)_{2(\boldsymbol{B} / \boldsymbol{B})}(\mathrm{OH})_{4}\right.$ and $\left.\mathrm{Ca}_{38}\left(\mathrm{PO}_{4}\right)_{20}\left(\mathrm{CO}_{3}\right)_{4(\boldsymbol{B} / \boldsymbol{B})}(\mathrm{OH})_{8}\right)$ substitution (major contribution), A/B $\left(\mathrm{Ca}_{20}\left(\mathrm{PO}_{4}\right)_{11}\left(\mathrm{CO}_{3}\right)_{2(A / B)}(\mathrm{OH})_{3}\right)$ substitution (minor contribution), and a fraction of isolated $\mathrm{B}$ sites.

\section{EXPERIMENTAL SECTION}

Syntheses of samples. n.a.CHAp: all experiments were conducted in a glovebox under flowing dry $\mathrm{N}_{2}$ gas. Standard precipitation of CHAp in aqueous solution (at room temperature) was performed. All solutions were first decarbonated (boiling them and using an argon flux during the syntheses). A solution of ammonium hydrogenphosphate $\left(\left(\mathrm{NH}_{4}\right)_{2} \mathrm{HPO}_{4}, 0.30 \mathrm{~mol} . \mathrm{L}^{-1}, \mathrm{pH} \sim 10\right)$ was added to a solution of calcium nitrate tetrahydrate $\left(\mathrm{Ca}\left(\mathrm{NO}_{3}\right)_{2} \cdot 4 \mathrm{H} 2 \mathrm{O}\right.$, 
0.50 mol. $\left.\mathrm{L}^{-1}, \mathrm{pH} \sim 5\right)$ using a titration apparatus (8o8 Titrando, Methrom, $\left.3 \mathrm{~mL} \cdot \mathrm{min}^{-1}\right)$. Carbonates were introduced by adding sodium hydrogencarbonate $\left(\mathrm{NaHCO}_{3}\right)$ to the phosphate solution. All experiments were performed under argon flux and magnetic stirring. The initial molar ratios were: $\mathrm{Ca}$ : 10, $\mathrm{P}: 6, \mathrm{CO}_{3}{ }^{2-}: 3$. After the addition of the phosphate solution, the obtained precipitates were further stirred for 24 hours. After centrifugation, the precipitates were rinsed 4 times with distilled water (final $\mathrm{pH}$ of water 7). All samples were then heat treated $\left(400^{\circ} \mathrm{C}\right)$ for 48 hours in order to eliminate remaining water and ammonia molecules. Elemental analyses: performed at the Centre d'Analyses CNRS, Vernaison, France. Found wt\%: Ca: 34.17, P: 15.66, C: $1.04, \mathrm{Na}: 0.33, \mathrm{~N}: 1.23 . \mathrm{CO}^{2-}$ wt\%: 5.20. CHAp: basically, the same protocol used for n.a.CHAp was implemented, using $\mathrm{NaH}^{13} \mathrm{CO}_{3}$ (fully labeled in ${ }^{13} \mathrm{C}$ ) as a source of carbonates. The same sample treatment (stirring, centrifugation, rinsing, heating at $400^{\circ} \mathrm{C}$ for 48 hours) was implemented. Found $\mathrm{wt} \%$ : Ca: 37.6o, P: 17.01, C: o.97, Na: 0.35, N: <0.10. $\mathrm{CO}_{3}{ }^{2-} \mathrm{wt} \%$ : 4.8o. Routine characterization (XRD, FTIR) of n.a.CHAp and CHAp are presented in Figures $\mathrm{S}_{9}$ and Sio.

Solid-state DNP/NMR experiments. Sample preparation for n.a.CHAp and CHAp: the TOTAPOL ${ }^{19}$ and $\mathrm{AMUPol}^{20}$ biradical polarizing agents were used in $\mathrm{D}_{2} \mathrm{O}(90) / \mathrm{H}_{2} \mathrm{O}(10)$ solutions. For TOTAPOL: $2.4 \mathrm{mg}$ were dissolved in $270 \mu \mathrm{L}$ of $\mathrm{D}_{2} \mathrm{O}$ and $30 \mu \mathrm{L}$ of $\mathrm{H}_{2} \mathrm{O}$ leading to a 20.0 mM.L ${ }^{-1}$ TOTAPOL solution. $30 \mathrm{mg}$ of sample of interest was impregnated with $15 \mu \mathrm{L}$ of the corresponding TOTAPOL solution. The mixture was then inserted in a $3.2 \mathrm{~mm}$ sapphire rotor and rapidly cooled down to $\sim 100 \mathrm{~K}$. The mass of sample of interest in the rotor was estimated to $\sim 15 \mathrm{mg}$. For AMUPol: $1.1 \mathrm{mg}$ were dissolved in $90 \mu \mathrm{L}$ of $\mathrm{D}_{2} \mathrm{O}$ and $10 \mu \mathrm{L}$ of $\mathrm{H}_{2} \mathrm{O}$ leading to a $15.0 \mathrm{mM} . \mathrm{L}^{-1}$ AMUPol solution. $~ 30 \mathrm{mg}$ of sample of interest was impregnated with $15 \mu \mathrm{L}$ of the corresponding AMUPol solution. Glycerol (glass former) was not used in this study. DNP/NMR: all DNP MAS experiments were recorded using a Bruker DNP-NMR AVANCE III $400 \mathrm{MHz}$ spectrometer equipped with a gyrotron and associated transmission line capable of delivering more than $5 \mathrm{~W}$ of $\sim 263 \mathrm{GHz}$ microwave irradiation at the sample. All experiments were recorded with a $3.2 \mathrm{~mm}$ HXY triple-resonance MAS probe at $v_{\mathrm{o}}\left({ }^{1} \mathrm{H}\right)=400.07 \mathrm{MHz}$ corresponding to the maximum ${ }^{1} \mathrm{H}$ enhancement field position for AMUPol at $v_{\mathrm{o}}\left(\mathrm{e}^{-}\right)=263.5 \mathrm{GHz}$, with the X-channel tuned to $v_{\mathrm{o}}\left({ }^{31} \mathrm{P}\right)=161.95 \mathrm{MHz}$ and the $\mathrm{Y}$-channel tuned to $v_{0}\left({ }^{13} \mathrm{C}\right)=100.60 \mathrm{MHz}$. The MAS rotation frequency was systematically fixed at $8 \mathrm{kHz}$. The $\varepsilon$ factor was measured for ${ }^{1} \mathrm{H}$ by recording $\mathrm{ON}$ and OFF experiments (single pulse experiment, SPE or spin echoes to avoid baseline distortions). $\varepsilon$ was measured independently for the solvent resonance and for the $\mathrm{OH}^{-}$resonance of the apatitic structures. ${ }^{1} \mathrm{H}(\pi / 2)=2.7 \mu \mathrm{s}(92.5 \mathrm{kHz})$. Systematic measurements of $\mathrm{T}_{1}\left({ }^{1} \mathrm{H}\right)$ were performed (saturation-recovery) in order to anticipate the relaxation delay in ${ }^{1} \mathrm{H}-\mathrm{X}$ DNP CP MAS experiments $\left(\sim 1.3 \mathrm{~T}_{1}\right)$. The collector current was optimized keeping in mind the corresponding increase of temperature of the sample during the $\mathrm{ON}$ experiments: $\sim+6 \mathrm{~K}$ for c.a. $5 \mathrm{~W}$ microwave irradiation at the sample. Hartmann-Hahn double (and triple) resonance profiles for ${ }^{31} \mathrm{P}$ and ${ }^{13} \mathrm{C}$ were recorded using $\mathrm{CHAp}$ as a model compound. For ${ }^{31} \mathrm{P}$ and ${ }^{13} \mathrm{C}$, ramped spin locking ${ }^{48}$ was implemented to facilitate the $C P$ transfer under MAS. SPINAL $-64^{49}$ was used for heteronuclear decoupling. The intensity of the signals was optimized by recording variable contact time experiments. For triple resonance experiments, a double CP transfer was implemented. Systematic control experiments were performed in order to prove the absence of any Zeeman contribution to the observed signals. 2D HETCOR CP MAS experiments were recorded under ${ }^{1} \mathrm{H}$ homonuclear decoupling using the Frequency Switched Lee-Goldburg (FSLG) scheme ${ }^{50}$. In the case of the ${ }^{13} \mathrm{C}-{ }^{13} \mathrm{C}$ recoupling experiment under MAS, the $\mathrm{SPC}_{5}$ scheme ${ }^{46}$ was implemented (with ${ }^{1} \mathrm{H} \rightarrow{ }^{13} \mathrm{C}$ CP MAS transfer prior to the recoupling pulses). Again, CHAp was used for the set-up of the experiments: RF power on the ${ }^{13} \mathrm{C}$ channel and the number of recoupling loops were carefully optimized $(4 \mathrm{~ms})$. The application of GB (Gaussian multiplication) apodization was carefully checked on both dimensions in order to clearly distinguish signals from wiggles. In order to strengthen that at least nine individual ${ }^{13} \mathrm{C}$ correlations are indeed observed, a nonwindowed 2D-FT plot is presented in Figure $\mathrm{S}_{7}$. One clearly notes that the extracted slices (noted i) to iv)) are fully comparable to those observed in Figure $3 c$ (with GB apodization). In other words, the wiggles present in Figure $3 c$ are not inducing deleterious distortions of the $2 \mathrm{D}$ spectrum. The NMR parameters used are the following. Figure 2a. NS (number of scans) $=4$, relaxation delay $=8.5$ $\mathrm{s}$, experimental time $\sim 30 \mathrm{~s}$. Figure $2 \mathrm{~b}$. NS $=16$, relaxation delay $=8.5 \mathrm{~s}$, contact time $=9 \mathrm{~ms}$, experimental time $\sim 2$ min. Figure $2 \mathrm{c}$. NS $=16$, relaxation delay $=8.5 \mathrm{~s}$, contact time $=9 \mathrm{~ms}$, experimental time $\sim 2 \mathrm{~min}$. Figure za. Red spectrum: $\mathrm{NS}=16$, relaxation delay $=8.5 \mathrm{~s}$, contact time $=$ $9 \mathrm{~ms}$, experimental time $\sim 2 \mathrm{~min}$. Black spectrum: $\mathrm{NS}=16$, relaxation delay $=6.5 \mathrm{~s}$, contact time $=9 \mathrm{~ms}$ and $20 \mathrm{~ms}$, experimental time $\sim 2 \mathrm{~min}$. Figure $3 \mathrm{~b}$. $\mathrm{NS}=16$, relaxation delay $=8.5 \mathrm{~s}$, number of $\mathrm{t}_{1}$ increments: 96 , contact time $=$ $9 \mathrm{~ms}$ and $20 \mathrm{~ms}$, experimental time $\sim 3 \mathrm{~h} 4 \mathrm{omin}$. Figure $3 \mathrm{c}$. $\mathrm{NS}=32$, relaxation delay $=8.5 \mathrm{~s}$, number of $\mathrm{t}_{1}$ increments: 96 , experimental time $\sim 7$ h.

\section{CONCLUSION}

In this contribution, we have clearly demonstrated that DNP is suitable for unprecedented description of substitutions in hydroxyapatite nanoparticles. The DNP gains are sufficient to implement dipolar based experiments which would have been impossible to set up using standard NMR conditions. The DNP approach is fully complementary to standard XRD and FTIR analyses as it allows the description of the substituants at an intermediate order range. The approach is general (in terms of efficient DNP solvent, biradical and sample preparation) and can be applied to all types of substitution as soon as one NMR active nucleus is present. Very interestingly, hydroxyap- 
atite is a prototype structure for DNP as quasi onedimensional proton spin diffusion is still active under moderate MAS and allows the description of a nanoparticle in its entirety. We have answered to two main structural questions regarding CHAp, namely the presence of local order and the clustering of carbonates. Most importantly, we have shown that: (i) the DNP approach can be easily extended to natural abundance $\left({ }^{13} \mathrm{C}\right)$ samples, (ii) DNP is obviously suitable for the study of natural nano-crystals such as those found in bones and teeth as their characteristic dimensions are much smaller than 100 $\mathrm{nm}$, (iii) the DNP derived structural models will act as valuable starting point for first principles calculations of NMR parameters and further independent validation.

\section{CAPTION OF FIGURES}

Figure 1. a) Schematic representation of pure HAp (here in the monoclinic form). O: red, H: black, Ca: blue, P: green. The same colour is used for all positions of a given atom ( 3 for $\mathrm{P}, 5$ for $\mathrm{Ca}, 1$ for $\mathrm{H}$ and 13 for $\mathrm{O}$ ). A sites correspond to $\mathrm{OH}^{-}$whereas $\mathrm{B}$ sites correspond to $\mathrm{PO}_{4}{ }^{3-}$ groups. The $\mathrm{OH}^{-}$ columns are represented schematically by cylinders (parallel to the $c$-axis). b) Simplified description of DNP process and ${ }^{1} \mathrm{H}-{ }^{1} \mathrm{H}$ spin diffusion (SD) along the $\mathrm{OH}^{-}$columns. In a first approximation, $\mathrm{SD}$ can be considered as one-dimensional $\left(D_{\mathrm{H}-\mathrm{H}}{ }^{\text {intra }} \sim 3.0 \mathrm{kHz}\right): \mathrm{H}_{2}$ is essentially coupled to $\mathrm{H}_{1}$ and $\mathrm{H}_{3}$ and so on for increasing $\mathrm{n}$. Columns are well separated $\left(D_{\mathrm{H}-\mathrm{H}}{ }^{\text {inter }} \sim 0.2 \mathrm{kHz}\right)$. The numerical estimations of $\Omega$ (transition rate) and D (diffusivity) are presented in Supporting information. In energetically relaxed models $\mathrm{s}^{38}$, $\mathrm{O}-\mathrm{H}-\mathrm{O}$ angle are approximately $180^{\circ}$ (but can be slightly different). Black triangles correspond to carbonate groups in A/B sites: adjacent $\mathrm{OH}^{-}$groups are rotated almost perpendicular to the $c$-axis ${ }^{38} . \mathrm{L} \sim 300 \AA$ corresponds to the longest chain of $\mathrm{OH}^{-}$in CHAp nanoparticles of $\varnothing \sim 30 \mathrm{~nm}$. Grey ovals: surface of the corresponding nanoparticle and \{solvent + biradicals $\}\left(\mathrm{D}_{2} \mathrm{O}(90) / \mathrm{H}_{2} \mathrm{O}(10)\right.$, TOTAPOL or AMUPol - see the Experimental section). The saturation of the EPR transitions of the biradicals by Microwave (MW) leads to efficient DNP transfer to the protons of the columns through cross effect (CE).

Figure 2. a) ${ }^{1} \mathrm{H}$ DNP MAS spectrum of CHAp ( $\left.\mathrm{T} \sim 100 \mathrm{~K}\right)$. OFF (without microwave, MW) and ON (with MW) spectra are presented for TOTAPOL and AMUPol. $\varepsilon\left({ }^{1} \mathrm{H}\right)$ corresponds to the ratio $\mathrm{ON} / \mathrm{OFF}^{18}$. S: DNP solvent. Protons of CHAp are located at o.o ppm $\left(\mathrm{OH}^{-}\right) . \varepsilon\left({ }^{1} \mathrm{H}\right)$ for the $\mathrm{OH}^{-}$resonance is comparable to the one of the solvent. b) ${ }^{1} \mathrm{H} \rightarrow{ }^{31} \mathrm{P}$ DNP CP MAS spectrum of CHAp. Insert: the ON and OFF spectra are strictly comparable. c) ${ }^{1} \mathrm{H} \rightarrow{ }^{13} \mathrm{C}$ DNP CP MAS spectrum of CHAp. Insert: ${ }^{13} \mathrm{C}$ spectral resolution and ${ }^{13} \mathrm{C}$ ranges for $\mathrm{A}, \mathrm{B}$ carbonates. Typical experimental time is given for each nucleus (in s or min.). *: spinning sidebands.

Figure 3. a) ${ }^{1} \mathrm{H} \rightarrow{ }^{13} \mathrm{C}$ (red) and ${ }^{1} \mathrm{H} \rightarrow{ }^{31} \mathrm{P} \rightarrow{ }^{13} \mathrm{C}$ (black) DNP CP MAS spectra of CHAp (with AMUPol). Spectra were obtained in 2 and 3 min., respectively. In grey: MW OFF. b) ${ }^{1} \mathrm{H} \rightarrow{ }^{31} \mathrm{P} \rightarrow{ }^{13} \mathrm{C}$ DNP HETCOR CP MAS spectrum of CHAp. Dashed lines are guidelines for the eyes. c) ${ }^{1} \mathrm{H} \rightarrow{ }^{13} \mathrm{C} \rightarrow{ }^{13} \mathrm{C}$ DNP DQ CP MAS ( $\left.\mathrm{SPC}_{5}\right)$ spectrum of $\mathrm{CHAp}^{46}$. Particular slices (noted i) $\rightarrow$ iv)) are highlighted on the right of the Figure. $A$ and $B{ }^{13} \mathrm{C}$ resonance ranges are indicated ${ }^{16}$ in orange and violet, respectively. The $2 \mathrm{D}$ experiment is presented with GB (see the Experimental section) whereas the slices are presented with standard FT (no GB). Vertical black arrows: ${ }^{13} \mathrm{C}$ correlations (A and B sites).

Figure 4. a) Pure HAp (monoclinic form). The c-axis is vertical (black double-arrow). As soon as $\mathrm{CO}_{3}{ }^{2-}$ groups are inserted, structures with $\mathrm{P}_{1}$ space group are basically considered $^{38}$. O: red, H: black, Ca: blue, P: green. The same colour is used for all positions of a given atom, for example green for $\mathrm{P}_{1}, \mathrm{P}_{2}$ and $\mathrm{P}_{3}$ (see also Figure 1a). All $\mathrm{O}$ atoms are omitted for clarity except those corresponding to $\mathrm{OH}^{-}$groups. The $\mathrm{Pi}-\mathrm{Pi}$ $(\mathrm{i}=1,2,3)$ zig-zag chains are in the main direction of the $c$ acis (green double-arrows). $\mathrm{d}_{(\mathrm{Pi}-\mathrm{Pi})}<4.2 \AA$ and $(\mathrm{Pi}-\mathrm{Pi}-\mathrm{Pi})$ $113^{\circ}$. b) Several schemes corresponding to $\mathrm{B} / \mathrm{B}$ associations exhibiting $\mathrm{d}_{(\mathrm{Pi}-\mathrm{Pi})}<4.2 \AA$ (all Ca atoms are omitted for clarity). The vertical black dashed line is a guideline for the eye to separate the left and right parts of the Figure (see main text). Left: two B sites corresponding to: $\square_{\mathrm{Ca} 2+}+2 \mathrm{CO}_{3}{ }^{2-}=$ $\mathrm{Ca}^{2+}+2 \mathrm{PO}_{4}^{3-}$ (eq. (3) in the main text). and $\square$ correspond to a $\mathrm{CO}_{3}{ }^{2-}$ group, and a $\mathrm{CO}_{3}{ }^{2-}$ group "associated" to a $\mathrm{Ca}^{2+}$ vacancy $\left(\square_{\mathrm{Ca} 2+}\right)$, respectively. Right: six $\left(C_{4}^{2}\right)$ possible configurations corresponding to four $\mathrm{CO}_{3}{ }^{2-}$ and two associated $\mathrm{Ca}^{2+}$ vacancies $\left(2 \square_{\mathrm{Ca} 2+}+4 \mathrm{CO}_{3}{ }^{2-}=2 \mathrm{Ca}^{2+}+4 \mathrm{PO}_{4}{ }^{3-}\right)$. The six chains are located nearby for clarity. For a given chain: the four carbonates are labeled $\mathrm{C}_{\mathrm{i}}(\mathrm{i}: 1 \rightarrow 4)$. We make the following assumption: $\delta_{\text {iso }}\left({ }^{13} \mathrm{C}_{\mathrm{i}}\right) \equiv \delta_{\mathrm{m}}(\mathrm{m}: 1 \rightarrow 8)$ is mainly dominated by the effect of the first neighbors along the given zig-zag chain, i.e. $\mathrm{P}, \mathrm{CO}_{3}{ }^{2-}\left({ }^{\circ}\right)$ or $\mathrm{CO}_{3}{ }^{2-}$ associated to a $\mathrm{Ca}^{2+}$ vacancy $(\square)$. As examples: $\square$ linked to $\{P, \square\}$ is named $\delta_{3}$; $\odot$ linked to $\{\ominus, \square\}$ is named $\delta_{5}$. Taking into account all six configurations, eight a priori different $\delta_{\text {iso }}\left({ }^{13} \mathrm{C}\right)$ are evidenced (noted $\delta_{\mathrm{i}}, \mathrm{i}=1 \rightarrow 8$ ). c) Theoretical dipolar ${ }^{13} \mathrm{C}-{ }^{13} \mathrm{C}$ correlation map associated to the six configurations and based on carbonates located on consecutive positions in the zig-zag chains. On-diagonal correlations are underlined in blue. As examples: $\delta_{3}$ is linked to $\delta_{4}$ in a zig-zag chain leading to $\left\{\delta_{3}, \delta_{4}\right\}$ off-diagonal $\times$ in the correlation map ; $\delta_{4}$ is linked to $\delta_{2,3,4,5}$ in the zig-zag chains leading to $\left\{\delta_{4}, \delta_{2,3,5}\right\}$ off-diagonal $\times$ and $\left\{\delta_{4}, \delta_{4}\right\}$ on-diagonal $\times$ in the correlation map. 
FIGURE 1

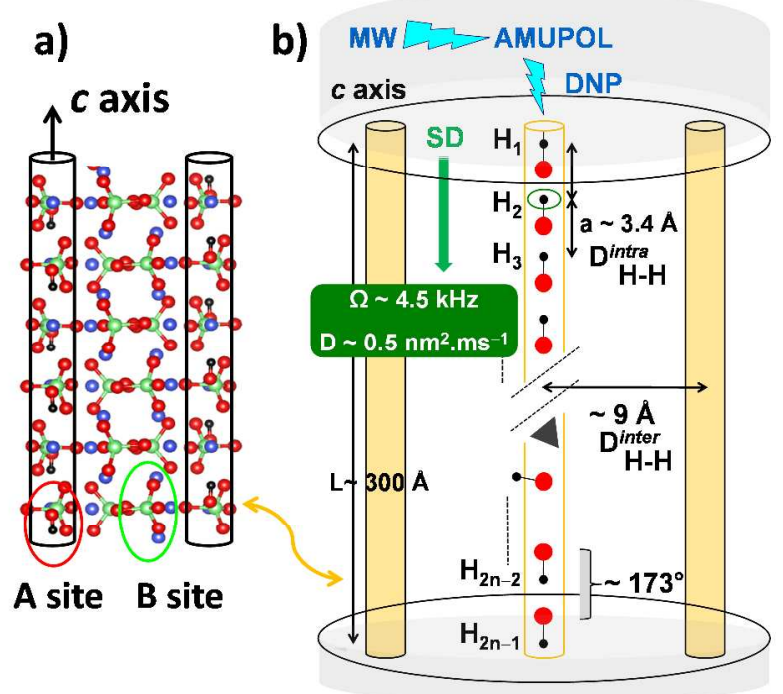

FIGURE 2
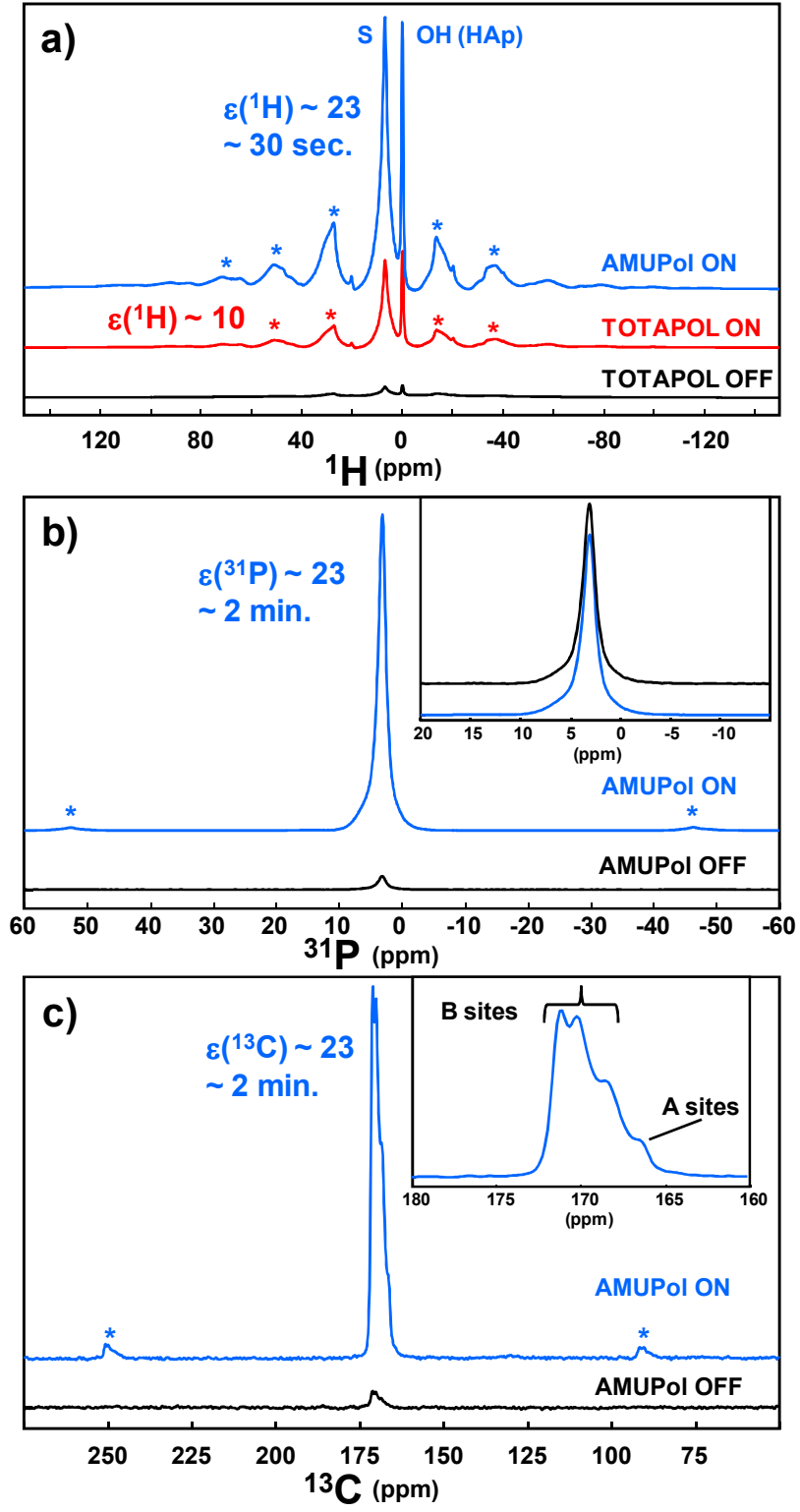
FIGURE 3
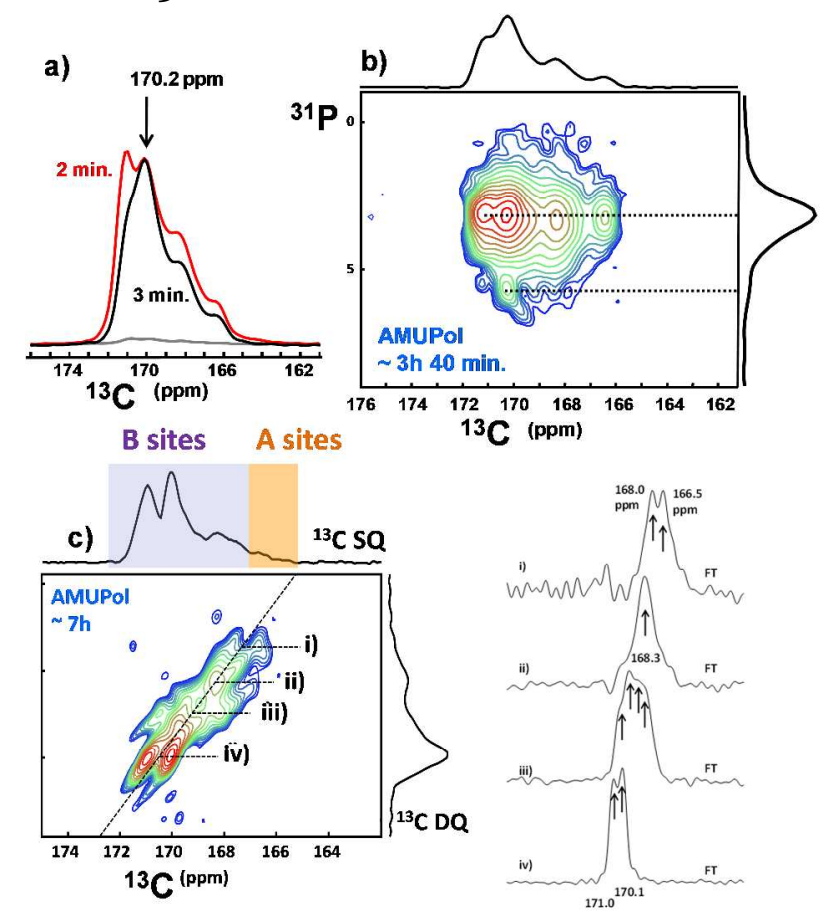

a)

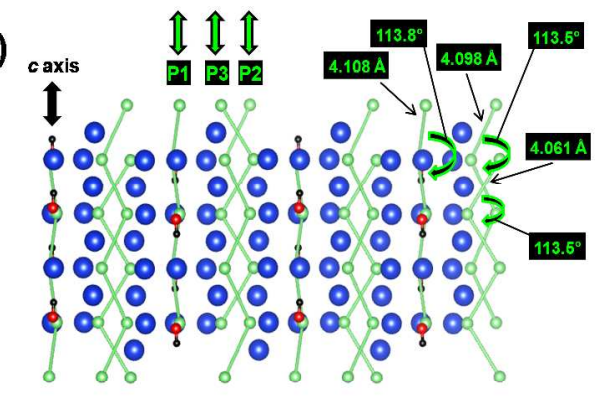

b)

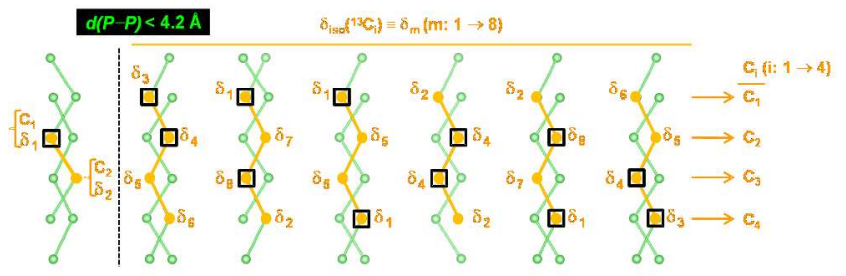

c)

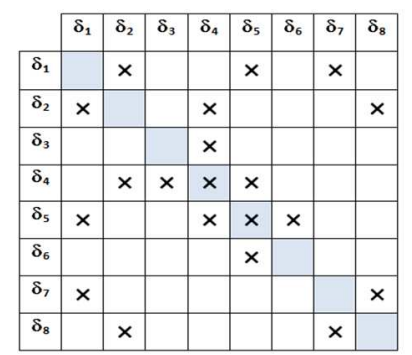

FIGURE 4

\section{ASSOCIATED CONTENT}

Supporting information: spin diffusion (SD) in HAp: modeling and orders of magnitude, TEM pictures of CHAp and n.a.CHAp, $2 \mathrm{D}{ }^{1} \mathrm{H} \rightarrow{ }^{31} \mathrm{P}$ HETCOR CP MAS spectra of CHAp obtained at room temperature (RT), ${ }^{1} \mathrm{H} \rightarrow{ }^{13} \mathrm{C}$ CP MAS spectra of CHAp at room temperature $(700 \mathrm{MHz})$ and $\mathrm{T} \sim 100 \mathrm{~K}$ (40o MHz), ${ }^{1} \mathrm{H} \rightarrow{ }^{13} \mathrm{C}$ CP MAS dynamics for CHAp at room temperature (300 MHz) and $\mathrm{T} \sim 100 \mathrm{~K}(400 \mathrm{MHz}),{ }^{1} \mathrm{H} \rightarrow{ }^{13} \mathrm{C}$ CP MAS spectra at variable contact time for CHAp and Na$\mathrm{HCO}_{3},{ }^{1} \mathrm{H} \rightarrow{ }^{31} \mathrm{P} \rightarrow{ }^{13} \mathrm{C}$ DNP HETCOR CP MAS spectrum of n.a.CHAp, DNP DQ CP MAS SPC 5 spectrum without any GB apodization on both dimensions (2D-FT plot), other B/B associations in the $(\mathrm{ab})$ plane and potential dipolar truncation, powder XDR and FTIR data for CHAp and n.a.CHAp. This material is available free of charge via the Internet at http://pubs.acs.org.

\section{AUTHOR INFORMATION}


Corresponding Author

* Christian BONHOMME (christian.bonhomme@upmc.fr)

Author Contributions

F.B., C.B., A.O. and S.H. initiated the work. C.C.-D, C.L., F.A., F.B. and C.B. performed the spectroscopic studies; L.B.-C., A.O. and S.H. performed the synthesis and first characterizations of the CHAp nanoparticles; the paper was mainly written by C.B.

\section{Notes}

The authors declare no competing financial interests.

\section{ACKNOWLEDGMENT}

The French Région Ile de France SESAME program is acknowledged for financial support (70o MHz spectrometer). C. Crevant is warmly acknowledged for early preparation of some of the samples studied in this contribution.

\section{REFERENCES}


${ }^{1}$. Elliott, J.C. Reviews in Mineralogy and Geochemistry 2002, 48, 427-453.

2. Carbonated hydroxyapatite, Fleet, M., Pan Stanford Publishing, 2015.

${ }^{3}$. Finkemeier, C.G. J. Bone Joint Surg. Am. 2002, 84, 454-464.

${ }^{4}$. Leventouri, T. Biomaterials 2006, 27, 3339-3342.

${ }^{5}$. Wilson, R.M.; Elliott, J.C.; Dowker, S.E.P.; Smith, R.I. Biomaterials 2004, 25, 2205-2213.

${ }^{6}$. Supova, M. Ceramics International 2015, 41, 9203-9231.

${ }^{7}$. Ren, F.; Ding, Y.; Leng, Y. J. Biomed. Mater. Res. Part A 2014, 102, 496-505.

${ }^{8}$. Yesinowski, J.P.; Eckert, H. J. Am. Chem. Soc. 1987, 109, 6274-6282.

9 . Cho, G.; Wu, Y.; Ackerman, J.L. Science 2003, 300, 1123-1127.

${ }^{10}$. Jäger, C.; Welzel, T.; Meyer-Zaika; W.; Epple, M. Magn. Reson. Chem. 2006, 44, 573-580.

${ }^{11}$. Ben Osman, M.; Diallo-Garcia; S.; Herledan, V.; Brouri, D.; Yoshioka ; Kubo, J.; Millot, Y.; Costentin, G. J. Phys. Chem. C 2015, 119, 23008-23020.

${ }^{12}$. McElderry, J.-D.P.; Zhu, P.; Mroue, K.H.; Xu, J.; Pavan, B.; Fang, M.; Zhao, G. McNerny, E.; Kohn, D.H.; Franceschi, R.T. et al. J. Solid State Chem. 2013, 206, 192-198.

13. Wang, Y.; Von Euw, S.; Fernandes, F.M. ; Cassaignon, S. ; Selmane, M. ; Laurent, G. ; Pehau-Arnaudet, G. ; Coelho, C. ; Bonhomme-Coury, L. ; Giraud-Guille, M.M. et al. Nature Mater. 2013, $12,1144-1153$.

${ }^{14}$. Wise, E.R.; Maltsev; S. Davies ; M.E., Duer, M. ; Jaeger C. ; Loveridge, N., Murray, R.C.; Reid, D.G. Chem. Mater. 2007, 19, 5055-5057.

${ }^{15}$. Reid, D.G.; Duer. M.J.; Murray, R.C.; Wise E.R. Chem. Mater 2008, 20, 3549-3950. 
${ }^{16}$. Beshah, K.; Rey, C.; Glimcher, M.J.; Shimizu, M., Griffin, R.G. J. Solid State Chem. 1990, 84, 7181 .

${ }^{17}$. Mason, H.E.; Kozlowski, A.; Phillips, B.L. Chem. Mater. 2008, 20, 294-302.

18 . Maly, T.; Debelouchina, G.T.; Bajaj, V.S.; Hu, K.-N.; Joo, C.-G.; Mak-Jurkauskas, L.; Sirigini, J.R.; van der Wel, J.R.S.; Herzfeld, J.; Temkin, R.J.; Griffin, R.G. J. Chem. Phys. 2008, 128, 052211-1-19.

${ }^{19}$. Song, C.; Hu, K.-N.; Joo, C.-G.; Swager, T. M.; Griffin, R.G. TOTAPOL J. Am. Chem. Soc., 2006, $128,11385-11390$.

${ }^{20}$. Sauvée, C. ; Rosay, M. ; Casano, G. ; Aussenac, F. ; Weber, R. T.; Ouari, O.; Tordo, P. Angew.

Chem. Int. Ed. 2013, 52, 10858-10861.

${ }^{21}$. Lesage, A.; Lelli, M.; Gajan, D.; Caporini, M. A.; Vitzthum, V.; Mieville, P.; Alauzun, J.; Roussey, A.; Thieuleux, C. Mehdi, A. et al. J. Am. Chem. Soc. 2010, 132, 15459-15461.

${ }^{22}$. Gelis, I. ;Vitzhum, V. ; Dhimole, N. ; Caporini, M. A. ; Schedlbauer, A.; Carnevale, D.; Connel, S.R. ; Fucini, P. ; Bodenhausen, G. J. Biomol. NMR 2013, 56, 85-93.

${ }^{23}$. Rossini, A.J. ; Zagdoun, A. ; Lelli, M. ; Lesage, A. ; Copéret, C. ; Emsley, L. Acc. Chem. Res. 2013, $46,1942-1951$.

24. Hirsh, D.A.; Rossini, A.J.; Emsley, L.; Schurko, R.W. Phys. Chem. Chem. Phys. 2016, 18, 25893-25904.

${ }^{25}$. Baudouin, D.; van Kalkeren, H.; Bornet, A.; Vuichoud, B.; Veyre, L., Cavailles, M.; Schwarzwalder, M.; Liao, C.; Gajan, D., Bodenhausen, G. et al. Chem. Sci. 2016, 7, 6846-6850.

${ }^{26}$. Chaudhari, S.R.; Berruyer, P.; Gajan, D.; Reiter, C.; Engelke, F.; Silverio, D.L.; Copéret, C.; Lelli, M.; Lesage, A.; Emsley, L. Phys. Chem. Chem. Phys. 2016, 18, 10616-10622.

27. Thankamony, L.A.S.; Lion, C.; Pourpoint, F.; Singh, B.; Perez Linde, A.J.; Carnevale, D.; Bodenhausen, G.; Vezin, H.; Lafon, O.; Polshettiwar, V. et al. Angew. Chem. Int. Ed. 2015, 54, 2190-2193.

${ }^{28}$. Lafon, O.; Rosay, M. ; Aussenac, F. ; Lu, X. ; Trébosc, J. ; Cristini, O. ; Kinowski, C. ; Touati, N. ; Vezin, H. ; Amoureux, J.P. Angew. Chem. Int. Ed. 2011, 50, 8367-8370.

${ }^{29}$. Kobayashi, T. ; Perras, F.A. ; Wei Goh, T. ; Metz, T. L.; Huang, W. ; Pruski, M. J. Phys. Chem. Lett. 2016, 7, 2322-2327.

${ }^{30}$.Takahashi, H.; Viverge, B.; Lee, D.; Rannou, P.; De Paëpe, G. Angew. Chem. Int. Ed. 2013, 52, 69796982.

${ }^{31}$. Lee, D. ; Bouleau, E. ; Saint-Bonnet, P. ; Hediger, S. ; De Paëpe, G. J. Magn. Reson. 2016, 264, 116124.

${ }^{32}$. Lee, D.; Hediger, S.; De Paëpe, G. Solid State NMR 2015, 66-67, 6-20. 
33 . Blanc, F.; Sperrin, L.; Jefferson, D.A.; Pawsey, S.; Rosay, Grey, C.P. J. Am. Chem. Soc. 2013, 135, 2975-2978.

${ }^{34}$. Le, D. ; Ziarelli, F. ; Phan, T.N.T. ; Mollica, G. ; Thureau, P.; Aussenac, F. ; Ouari, O. ; Gigmes, D. ; Tordo, P. ; Viel, S. Macromol. Rapid Comm. 2015, 36, 1416-1421.

35 . Ouari, O. ; Phan, T. ; Ziarelli, F. ; Casano, G. ; Aussenac, F. ; Thureau, P. ; Gigmes, D. ; Tordo, P. ; Viel, S. ACS Macro Lett. 2013, 2, 715-719.

36 . Lee, D. ; Leroy, C. ; Crevant, C. ; Bonhomme-Coury ; L., F. Babonneau ; Laurencin, D. ; Bonhomme, C. ; De Paëpe, G. Nature Commun., 2017, 8, 14104 (2017).

${ }^{37}$. Fleet, M.E.; Liu, X. Am. Miner. 2011, 96, 1148-1157.

38 . Peroos, S.; Du, Z.; de Leeuw, N. H. Biomaterials 2006, 27, 2150-2161.

${ }^{39}$. Astala, R. ; Stott, M.J. Chem. Mater. 2005, 17, 4125-4133.

${ }^{40}$. Ulian, G.; Valdre, G.; Corno, M.; Ugliengo, P. Am. Miner. 2014, 99, 117-127.

41 . van der Wel, P. C. A., Hu, K.-N., Lewandowski, Griffin, R. G. J. Am. Chem. Soc., 2006, 128, 1084010846 .

42 . Rossini, A.J.; Widdifield, C.M.; Zagdoun, A.; Lelli, M.; Schwaezwälder, M.; Copéret, C.; Lesage, A.; Emsley, L. J. Am. Chem. Soc. 2014, 136, 2324-2334.

${ }^{43}$ Rossini, A. J.; Zagdoun, A.; Hegner, F. S.; Schwarzwälder, M.; Gajan, D.; Copéret, C.; Lesage, A.; Emsley, L. J. Am. Chem. Soc. 2012, 134, 16899-16908.

${ }^{44}$ Lafon, O.; Thankamony, A. S. L.; Kobayashi, T.; Carnevale, D.; Vitzthum, V.; Slowing, II; Kandel, K.; Vezin, H.; Amoureux, J. P.; Bodenhausen, G.; Pruski, M. J. Phys. Chem. C 2013, 117, 1375-1382.

45 Multidimensional solid-state NMR and Polymers, Schmidt-Rohr, K. \& Spiess, H.W., Academic Press, 1994.

46. Hohwy, M.; Rienstra, C.M.; Jaroniec, C.P.; Griffin, R.G. J. Chem. Phys. 1999, 110, 7983-7992.

47 . Babonneau, F.; Bonhomme, C.; Hayakawa, S.; Osaka, A. MRS Proceedings, Fall Meeting, Boston, e-paper, 0984-MM06-05 (2007).

${ }^{48}$. Metz, G.; Wu, X.L.; Smith, S.O. J. Magn. Reson. A 1994, 110, 219-227.

${ }^{49}$. Fung, B.M.; Khitrin, A.; Ermolaev, K. J. Magn. Reson. 2000, 142, 97-101.

${ }^{50}$. Coelho, C.; Rocha, J.; Madhu, P. K.; Mafra, L. J. Magn. Reson. 2008, 194, 264-282. 